\title{
La libertad de expresión en el mercado de las ideas
}

\author{
Freedom of Speech in the Market of Ideas
}

\author{
John Durham PETERS \\ Yale University (EEUU) \\ john.peters@yale.edu
}

RECIBIDO: 21/09/2017 / ACEPTADO 23/10/2017

\begin{abstract}
Resumen: El ensayo presenta una reflexión histórica y critica de las premisas teóricas y culturales del principio clave del liberalismo, la libertad de expresión, de sus desarrollos y de los retos actuales que lo desafían. A partir de la exposición de los tres elementos principales (una creencia en el carácter sagrado de la vocación de la prensa y de la comunicación en general como vehículo para la iluminación pública; una visión estoica y humanista de la mente humana y de los deberes del ciudadano, y una filosofía de la historia según la cual finalmente el error conducirá a la verdad y el mal producirá el bien), el autor expone los problemas que considera decisivos en el próximo futuro: el olvido de la antigüedad clásica y de la noción elegante del ciudadano-soldado (ligado a la decadencia de la cultura de la imprenta); la pérdida de confianza en el progreso moral; la globalización; la transformación de la infraestructura de los medios y de la comunicación; el resurgir de la religión.
\end{abstract}

Palabras clave: libertad de expresión; Liberalismo; Estoicismo; globalización; progreso; cultura.

\begin{abstract}
The article presents a historical and critical reflection of the theoretical and cultural premises of the key principle of liberalism, freedom of expression, its developments and the current challenges that challenge it. From the exposition of the three main elements (a belief in the sacredness of the vocation of the press and of communication in general as a vehicle for public enlightenment, a stoic and humanist vision of the human mind and the duties of the citizen, and a philosophy of history according to which the error will eventually lead to truth and evil will produce good), the author exposes the problems he considers decisive in the near future: forgetting classical antiquity and the elegant notion of the citizen-soldier (linked to the decadence of the culture of the printing press); loss of confidence in moral progress; the globalization; the transformation of media infrastructure and communication the resurgence of religion.
\end{abstract}

Keywords: freedom of expression; Liberalism; Stoicism; globalization; progress; culture.

L

a libertad de expresión se funda en una filosofía social que de modo aproximativo podría denominarse liberalismo. En ella hay tres ideas fundamentales: en primer lugar, una creencia en el carácter sagrado de la vocación de la prensa y de la comunicación en general como vehículo para la iluminación pública; una visión estoica y humanista de la mente humana y de los deberes del ciudadano, y por último, una filosofía de la historia según la cual finalmente el error conducirá a la verdad y el mal producirá el bien. En este momento, a mi entender, esas ideas liberales tropiezan con diversas amenazas. Voy a describir cinco de ellas: la devaluación del estoicismo como modelo de ciudadano, la pérdida de confianza en el progreso histórico, la globalización,

* El artículo recoge una conferencia impartida por el autor en la Universidad de Navarra antes de que ocurrieran hechos como los atentados de Charlie Hebdò a los que, por ese motivo, no se alude. 
la transformación de los medios electrónicos, y el regreso de la religión al escenario mundial.

En un momento de cambio social y cultural, no es fácil saber qué pensar acerca de la libertad de expresión. Entiendo que se trata de una cuestión filosófica, sociológica e histórica que requiere explorar previamente su entramado intelectual. $\mathrm{Y}$ aunque muchos pueden considerarse precursores de las doctrinas liberales de la libertad de expresión, hay dos figuras, John Stuart Mill (1806-1873) y Oliver Wendell Holmes Jr. (1841-1935), un filósofo y un juez, un inglés y un americano, que constituyen un buen punto de partida para introducirse en la tradición liberal. El término «liberalismo», acuñado en España alrededor de 1820, es el más resbaladizo de todos los términos políticos modernos. Desde finales del siglo XIX el término ha seguido una doble trayectoria social y económica. En Europa y en Australia, «liberal» implica una posición conservadora, lo que significa apoyar el libre mercado; en los Estados Unidos, en cambio, «liberal» supone una postura social-democráta, esto es, de apoyo al papel del Estado en el mantenimiento del bienestar social junto con un respeto a la indomesticable diversidad de las opciones humanas. El término «neo-liberal», como es sabido, se asienta en la rama del liberalismo que apoya el libre mercado, aunque trate al mismo tiempo de participar del glamour de lo «social». Para Mill, que en realidad es representante de ambas ramas, el libre mercado y la libertad de expresión son dos caras de la misma moneda: la soberanía del individuo para actuar como a él o a ella le parezca mejor (dentro de los límites del daño a otros). Esta mezcla explosiva ha alumbrado desde entonces elementos variados e incompatibles entre sí: liberal puede tener un significado teológico, o puede significar socialmente tolerante, mentalmente abierto, mentalmente difuso, desregulatorio, a favor de la intervención estatal, agresivamente capitalista, etc. Es un término intratable que sin embargo, a pesar de, o quizá por su carácter resbaladizo, estamos condenados a usar.

El pensamiento, tanto el popular como el académico, sobre la relación entre democracia y comunicación sigue estando condicionado en buena medida por la versión heroica de la historia liberal acerca de la libertad de expresión (aunque en su forma dominante esta historia sea un producto de mediados del siglo veinte). La historia habla de revolucionarios valientes y de impresores y editores llenos de coraje que arriesgaron vida, miembros y fortuna por desafiar la censura de la corona o de la Iglesia. Al ignorar las inhibiciones y los edictos de los censores, estos héroes (según cuenta la historia) formaron un «mercado de ideas» en el que todas, fueran buenas, malas o feas, pudieran ser evaluadas según sus méritos propios, y cuyo precio podía determinarse en libre y abierta 
competición. Hay que hacer notar que esta metáfora es producto de finales del siglo veinte y constituye una guía poco segura tanto para la historia de las ideas liberales como para la práctica del periodismo democrático ${ }^{1}$. Se supone que esta plaza pública era el motor de la vida democrática y el lugar que hace posible el florecimiento público del logos, tan central para la democracia. En las naciones protestantes la prensa escrita asumía un estatus cercano al mitológico como un agente histórico-universal de ilustración y emancipación y como la institución que hace posible en último término la soberanía popular. Walter Lippmann llamó al periódico «la Biblia de la democracia». La prensa tuvo un papel privilegiado en la divulgación de noticias y opiniones; todo ciudadano tenía la posibilidad de hablar de la verdad. Esta historia fue particularmente fuerte en la Ilustración radical, en pensadores como Milton, Spinoza, Catón ${ }^{2}$, Voltaire y Thomas Paine, y a menudo tuvo un tinte anticatólico. Se hablaba de la censura como del mal supremo que era utilizada por imperios absolutos como España, Francia o Turquía. Los liberales anglófonos creían ser la mejor alternativa a la Inquisición española ${ }^{3}$ Ya en las primeras narraciones de la teoría moderna de la libertad de expresión encontramos una maniobra geopolítica tras la proclamación por algunas naciones de una superioridad moral unida a la invocación de la libertad de expresión y la prensa libre. La libertad de expresión nunca fue sólo una posición ética: siempre envolvió una cierta forma de supremacía política y vanagloria cultural por parte de sus proponentes.

Un segundo elemento clave en el entramado intelectual de la libertad de expresión fue la imagen clásica-elegante del yo, alma o ego. El ciudadano se construye a partir del modelo del caballero-soldado que está vigilante, es fuerte y capaz de autotrascendencia. Su autocontrol se pone de manifiesto en su habilidad para resistir sin queja el dolor y la incomodidad. Mill hablaba del ciudadano como un soldado de guardia en un puesto militar, que se quedaría dormido sin el estímulo de un debate abierto, y las metáforas de Holmes sobre la libre expresión fueron a menudo más militares incluso. Sostiene una ética 'de contrarios' que aparece con claridad en su afirmación de que la esencia de la libertad de expresión no es «pensamiento libre para aquellos que coinciden

1 Cfr. Peters, J. D., «'The Marketplace of Ideas’: a Histoy of the Concept», en A. Calabrese y C. SpARKS (eds.), Toward a Political Economy of Culture: Capitalism and Communication in the Twenty-First Century, Rowman and Littlefield, 2004, pp. 65-82.

2 NE. Cato se refiere originalmente a las Cato's Letters, ensayos políticos escritos con ese seudónimo por John Trenchard y Thomas Gordon en el primer tercio del siglo XVIII.

3 Peters, E., Inquisition, Free Press, New York, 1988. 
con nosotros sino libertad para el pensamiento de aquellos a los que odiamos» ${ }^{4}$. Su visión de la esfera pública no era tanto la de una plaza abierta a puntos de vista que compiten, sino más bien la de un campo de batalla darwiniano en el que doctrinas diferentes luchan por la supremacía, incluyendo doctrinas que muchos podría considerar como abominables. De forma aún más contundente, su colega en la Corte Suprema, el juez Louis Brandeis, elogió el poder de la libertad de expresión para enmendar «doctrinas perniciosas». En casos judiciales posteriores se habla de las manifestaciones de expresión de contenido abominable como de una «medicina fuerte» para una sociedad libre. Tal actitud permisiva se basa en la idea de que esas palabras no nos pueden hacer daño; más bien nos hacen fuertes moralmente al suponer un enérgico ejercicio ético. Las raíces de esta actitud descansan en la ética estoica de la abnegación, que nos llega desde Cicerón y Séneca a través del humanismo renacentista. Se encuentra en los clásicos del liberalismo inglés, en Locke, Adam Smith, y Mill, todos ellos claramente bajo la influencia del pensamiento ético estoico. En el estoicismo griego y romano el paradigma del orden político y moral es el orden natural cósmico, frente a cuya grandeza el dolor personal palidece hasta la insignificancia. Como kosmopolites o ciudadano del mundo, el estoico pasa por encima de lo malo y busca el bien público superior. Este masoquismo en relación al dolor aparece a menudo en ideas post-estoicas sobre la libertad de expresión. Podríamos llamar «masoquismo homeopático», a la idea de que, como el anciano rey Mithridates, podemos tomar veneno en pequeñas dosis para evitar morir por su causa.

El tercer elemento clave en las ideas de la libertad de expresión es una filosofía de la historia que cree en una redención última frente al mal y en que la verdad triunfará al final. Esto no es exactamente lo mismo que la gran narración decimonónica del progreso histórico, aunque tengan fuentes comunes. La fuente de esta confianza en el triunfo del bien sobre el mal y de la verdad sobre el error es, en último término, la teología cristiana de la redención, aunque rara vez sea reconocida como tal por los pensadores liberales. La idea de una felix culpa, un delito feliz, o caída afortunada es el telón de fondo de una defensa liberal de la libertad de expresión. En la Areopagítica de John Milton (1644), una defensa de la prensa sin controles que se ha llegado a ver como uno de los documentos fundadores de la teoría de la libertad de expresión, esta teología aparece explícitamente. Milton fue un cristiano radical, no un liberal

4 U.S. v. Schwimmer, 279 US 644 (1929), at. 644-5, voto disidente del juez Holmes. 
moderno, y defendió la guerra abierta entre verdad y falsedad sobre la base de que el mundo, como en la parábola bíblica del campo sembrado con trigo y cizaña, era un terreno de prueba que requiere una lucha real entre opciones diversas. El antagonismo ideológico era la condición de nuestra perfección moral. Milton no tenía duda acerca de que la verdad (como él la entendía) triunfaría, aunque muchos han señalado que su gran poema épico, El Paraíso Perdido, escenario de una batalla dramática entre el bien y el mal, otorga los mejores discursos a Satanás y a otros enemigos de Dios. Ya desde entonces, los abogados de la libertad parecen encontrar un extraño placer en consentir la escenificación de discursos perturbadores como si eso constituyera una prueba más fuerte de la solidez de sus principios. Los periodistas y editores rara vez han profundizado en las dificultades de la prosa o la poesía de Milton, pero a menudo argumentan que es mejor publicar algo potencialmente conflictivo que suprimirlo, en la confianza de que hacer públicas las alternativas constituye el mejor modo de permitir la crítica de las ideas desechables. El principio de que el tiempo revelará la verdad y de que el mundo es suficientemente fuerte como para descubrir lo real de entre lo falso es lo que yo llamo «la teodicea liberal».

De este entramado histórico-intelectual se siguen algunos problemas si consideramos el futuro de la libertad de expresión desde una perspectiva global.

El primero es el olvido de la antigüedad clásica y de la noción elegante del ciudadano-soldado (que está ligado a la decadencia de la cultura de la imprenta). En España, los escritos de Séneca y la influencia del Humanismo renacentista propiciaron durante largo tiempo una cierta visión de la personalidad del ciudadano: moderado, controlado, estoico, generoso. En el mundo angloamericano, también los ideales caballerosos del honor y la autodisciplina aportaron durante mucho tiempo una psicología de la ciudadanía. A comienzos del siglo veinte, la objetividad profesional había comenzado a reemplazar al autocontrol del caballero como norma moral para las clases altas, pero persistía buena parte del mismo entramado mental: sacrificio, renuncia a las emociones o el propio interés, habilidad para formular juicios racionalmente correctos. A finales del siglo veinte, ese modelo de ciudadano fue puesto en cuestión desde diversas perspectivas. Las feministas condenaban la masculinidad implícita en la práctica del sacrificio y la renuncia frente a los sentimientos y a la comunidad. Los teóricos de la raza hablaban como de un «privilegio blanco» el que algunos pudieran acogerse a un espacio de racionalidad libre condicionantes - espacio de pura humanidad que había sido negado histórica- 
mente a tanta gente de color-. Y los marxistas atacaban tanto al noble como al burgués en cuanto que posiciones elitistas en la jerarquía de clases, proponiendo en cambio otras formas de subjetividad más «revolucionarias» ${ }^{5}$. Y para finales del siglo XX habían desaparecido casi totalmente los últimos vestigios de literatura griega y romana en la formación de los funcionarios.

La mayor parte de estas críticas son procedentes y conviene tenerlas en cuenta. Claramente, moldear la esfera pública a imagen de un campo de batalla o deleitarse en la propia la capacidad de afrontar las ofensas no son opciones globalmente viables en el siglo veintiuno. Los liberales no siempre han dado una explicación satisfactoria de lo que significa ser humano y ser persona y una ciudadanía sociológicamente más diversa exige también una más compleja explicación de la psicología y de los rituales cotidianos de la condición de ciudadano, que acoja a mujeres, inmigrantes, ancianos, minusválidos, subculturas, en otras palabras, a «los otros» como les gusta decir a los teóricos franceses en la estela de Emmanuel Levinas. Los amigos de la libertad tienen hoy una doble tarea: desarrollar una psicología más democrática de la ciudadanía y rescatar lo que todavía está vivo de la tradición estoica. Para esta tarea, el camino más prometedor desde mi punto de vista es unir el énfasis estoico en el espíritu público de desinterés con la más reciente apelación multicultural al respeto a la diferencia. Un estoicismo de escucha y respeto puede unir lo mejor de lo antiguo con lo nuevo. En la práctica esto significará reconocer una nueva ética del saber estar.

Un segundo reto es la pérdida de confianza en el progreso moral. Gran parte del contenido del pensamiento liberal aflora a comienzos de la modernidad, un tiempo conocido por su confianza en el poder de la verdad para iluminar. Los filósofos tenían algunas veces ideas extrañamente ambiciosas acerca del poder de la razón. Espinoza, en su confianza en la transparencia de la luz, escribió que «la verdad se revela a sí misma». Leibniz se atrevió a escribir una «teodicea» con la que creyó poder explicar la presencia del sufrimiento en el mundo (ironizada como es conocido por el Cándido de Voltaire). Los artistas de comienzos del periodo moderno creyeron con igual firmeza que mirar de frente a la oscuridad constituía un imperativo moral. Milton, como se hizo notar anteriormente, dedicó espléndida y persuasiva poesía a Satanás y a sus servidores en el Paraíso Perdido sin preocuparle estar contribuyendo a su causa. J.S. Bach atri-

5 Gran parte de este debate se desarrolló en torno a la obra de Habermas. Ver Habermas and the Public Sphere, ed. Craig Calhoun, MIT Press, Cambridge 1992. 
buyó a Judas, Pilatos y al Sumo Pontífice partes preciosas en la Pasión según san Mateo. Al dar a los villanos de su narración voces atractivas, Bach no temió que su audiencia se sintiera seducida por ellos; pensaba que sus oyentes escucharían la historia completa y distinguirían el papel que corresponde a cada figura. De hecho, tanto Milton como Bach parecían creer que su responsabilidad religiosa en cuanto que cristianos era dibujar el alcance total del pecado con todo el poder de su arte. En esto eran parte de una serie más amplia de pensadores cristianos que entendían que presentar vívidamente la maldad era un deber moral y estético para cualquiera que tratara de contar la historia de la salvación, una larga lista que incluye a Dante, S. Agustín y San Pablo.

Parte de esta confianza en el papel educacional y ético de la controversia persiste hoy en la filosofía de la libertad de expresión, si bien la confianza en que la historia y el debate abierto conseguirán deslindar la verdad del error es, en general, mucho más débil en el siglo veintiuno. El marxismo que quizá haya sido el más importante esfuerzo secular para proporcionar una teodicea y un destino a la historia humana yace hecho jirones. ¿Y cuál puede ser nuestra fe en cualquier narración o teodicea tras un siglo de genocidios? El siglo diecinueve logró mucho de su confianza en el progreso moral gracias a cerca de cien años de paz dentro de las fronteras de Europa, a la casi completa eliminación de la tortura, a la abolición de la esclavitud, a la emancipación de la mujer y a campañas en contra de la crueldad con los animales, una serie de aspiraciones históricas que Mill llamó «suavización de los modales». A comienzos del siglo XXI el progreso está hecho añicos, si es que existe: los pensadores ya no creen en el progreso de la civilización como algo real. Sin duda, hay formas de progreso en ámbitos específicos (en técnicas médicas o en chips de silicona, por ejemplo) pero nadie puede creer realmente en un progreso moral del modo en que un día lo hicieron muchos pensadores ilustrados o del diecinueve. El progreso, como sabemos hoy, es específico y parcial. Dado el colapso de la fe en que la verdad se revela a sí misma automáticamente, ¿podría la filosofía de la libertad de expresión actuar sin su esperanza y optimismo acostumbrados? En general hoy somos mucho más pesimistas acerca de la capacidad ilustradora del debate; de oír todas las voces. La investigación empírica en comunicación, con sus ciertamente decepcionantes descubrimientos de los efectos limitados, riesgo selectivo, ignorancia racional, y disfunciones narcotizantes, entre otros, no nos ha dado motivos para la esperanza. La libertad de expresión es un accidente de lo que Horkheimer y Adorno llamaron la dialéctica de la ilustración. El proyecto de mostrar el error ha concluido mostrando los errores inherentes al proyecto mismo. 
Un tercer reto es la globalización. Prácticamente todas las naciones de la tierra apoyan formalmente la libertad de expresión. Pero desde hace mucho, una cultura de la libertad de expresión fuerte se da sólo en las naciones postProtestantes. Hay estudios de modernización comparativos que sugieren que las sociedades con fuerte apoyo a la libertad de expresión se encuentran en el Norte de Europa y América, a las que se unen Australia y Nueva Zelanda ${ }^{6}$. En la opinión de la elite intelectual mundialmente hay enormes diferencias. En los debates de posguerra sostenidos en el seno de Naciones Unidas los delegados de diversos países mantenían también ideas muy diferentes sobre la responsabilidad social de la prensa, el derecho de réplica y la legitimidad de manifestaciones contrarias a la decencia; sólo los Estados Unidos, Gran Bretaña, Holanda y Australia apoyaron siempre libertades de prensa fuertes ${ }^{7}$. Más recientemente, un estudio comparativo de opinión pública entre americanos, rusos moscovitas, árabes israelíes, judíos israelíes y gente de Hong Kong, revela que hay diferentes patrones de apoyo a la libertad de expresión y a los derechos de los medios que varía dependiendo de factores demográficos como la educación, el género y los ingresos. Los ricos y educados apoyan la libertad de expresión más vigorosamente, quizá porque tienen acceso a los medios de expresión, pero también seguridad contra las consecuencias sociales negativas que pueda tener hablar. El género es el indicador más robusto del apoyo a la libertad de la prensa: los hombres están mucho más a favor de que los medios puedan publicar lo que quieran que las mujeres. Los datos, en suma, «sugieren que la gente que se siente más segura dentro de la sociedad es la que se inclina más a defender la libertad de expresión ${ }^{8}$. Las raíces culturales de la libre expresión son más fuertes en los países que comparten una historia particular, la reforma protestante, la racionalización jurídico-burocrática y el proceso de civilización.

La libertad de expresión es un lujo que se pueden permitir las sociedades que han alcanzado un determinado nivel de estabilidad y prosperidad. Hay una forma de potencial privilegio imperial, un exceso de seguridad en poner de manifiesto la fuerza del propio deseo de tolerar. Lo cierto es que se hace

6 Ver Inglehart, R. y BakeR, W. E.; «Modernization, Cultural Change and the Persistence of Tradicional Values», American Sociological Review, 65 (2000), pp. 19-51.

7 CMiel, K., «Human Rights, Freedom of Information and the Origins of Third World Solidarity», en M. P. BRADLEY y P. PETRO (ed.), Truth Claims: Representation and Human Rights, Rutgerds University Press, New Brunswick, NJ, 2002, pp. 107-130.

8 Andsager, J. L.; Wyatt, R. O. y MarTin, E., Free Expression and Five Democratic Publics: Support for Individual and Media Rights, Hampton, Creskill, NJ, 2004, passim y 265. 
necesaria una base intercultural de ideas sobre el mal y la libertad más rica. La libertad de expresión tiene una dimensión psicodinámica y cultural; es, en cierto modo, un fruto peculiar de la cultura europea que se asienta sobre premisas culturales profundas que no están globalizadas. A la cabeza entre ellas está el valor extremo que se da a andar al borde del abismo. Europa ha heredado de fuentes griegas, judías, romanas y cristianas, nociones acerca de lo beneficioso de descender a los infiernos con fines educativos o incluso redentores. Desde la Biblia a Milton o Rimbaud, desde Homero a Virgilio, de Dante a Dostoyevsky, a la literatura europea le gusta contar historias sobre el valor redentor que tiene en último término pasar una temporada en el infierno. La confianza en que podremos sobrevivir a esa exposición al lado oscuro es uno de los telones de fondo de la idea liberal de la libertad de expresión. Tal confianza es alimentada por la ética estoica del autodominio y la fortaleza, así como por la creencia cristiana -explícita en Pablo, Agustín, Dante y Milton, y profundamente deudora de la Biblia judía-, de que la transgresión puede conducir a un buen fin. El pecado de Adán y Eva puede verse como una forma de desobediencia civil que impulsa la historia de la salvación humana. De igual modo, hay corrientes en el pensamiento mesiánico judío que juegan con la herejía de la «redención a través del pecado». Los cristianos han atesorado la noción de felix culpa o crimen afortunado, y han atesorado también una larga historia de representación devota de su Dios en un estado sangrante y dolorido. Al contemplar una imagen de la crucifixión, el creyente ve, más allá de la ofensa y de los golpes, la gracia y el perdón. La muerte más degradante puede ser, para él, un signo de triunfo y una visión de la devoción más dulce. La cultura cristiana prepara para cierta clase de lectura irónica -la habilidad para descubrir en las más abyectas formas de existencia un especial poder redentor-. Esta habilidad requiere un particular entrenamiento cultural y una trayectoria histórica que quizá pueda no ser globalmente asumida.

En una esfera pública global, los países ricos pueden parecer ofensivamente arrogantes en su apoyo a la libertad de expresión. Nada ilustra mejor este punto que la controversia sobre las viñetas de Mahoma de comienzos del 2006. Aquí la libertad de expresión dejó de ser una ideología neutral para convertirse en el campo de batalla mismo. Los hechos del caso son bien conocidos?. Flemming

9 La mejor y más interesante fuente acerca de esta controversia es KUNELIUS, R.; EIDE, E.; HAHN, O. y SCHRÖDER, R. (eds.), Reading the Mohammed Cartoons Controversy: An International Analysis of Press Discourses on Free Speech and Political Spin, Projectverlag, Bochum 2007. 
Rose, editor del periódico danés conservador Jyllands-Posten, encargó a 25 dibujantes daneses en septiembre de 2005 dibujar al profeta Mahoma. En una forma clásica de andar al borde del abismo, Rose buscaba contrarrestar lo que percibía como una tendencia a la autocensura entre sus colegas al cubrir o representar el Islam. Su periódico finalmente publicó doce viñetas en septiembre de 2005, incluyendo el muy conocido dibujo de Mahoma con un turbante en forma de bomba. Los dibujos fueron publicados posteriormente en Egipto, Noruega y Alemania y se discute la causa inmediata pero el asunto estalló con toda su fuerza en febrero de 2006. El batir de las alas de una mariposa puede causar un tifón, dicen, y las caricaturas publicadas en un pequeño país nórdico desencadenaron de algún modo una secuencia de eventos que barrió el mundo y en el que 130 personas perdieron la vida. Una pequeña causa para un gran efecto: esta fórmula de la teoría del caos es ciertamente verdad en este caso.

Los periodistas, editores y políticos europeos parecieron genuinamente sorprendidos por la reacción de muchos musulmanes, pero además no fueron capaces de evitar manifestar un sentimiento de autosatisfacción por sus sociedades libres y abiertas. La referencia al masoquismo homeopático fue utilizada una y otra vez por los que apoyaban la publicación de las viñetas: todos deberíamos beber el veneno del mal en pequeñas dosis para hacernos capaces de libertad y aquellos que no puedan tolerar tan fuerte medicina no están preparados para la democracia. Tal arrogancia, con su implicación de que aquellos que dudan ante el mal son de alguna manera moralmente deficientes, no puede por menos que alejar a los musulmanes moderados que respetan su religión sinceramente, aunque sin sentir habitualmente simpatía por los escasos extremistas que les rodean. El efecto secundario de una defensa absolutista de la libertad de expresión es un movimiento político de dominación global, un acto de Realpolitik: anuncia al mundo que Europa tiene unos valores más elevados y mejores que los del Islam. Una proclamación estridente de la libertad de expresión nunca ha sido una mera expresión de un ideal, por el contrario, siempre ha tenido consecuencias geopolíticas. Los teóricos desde Milton a Mill oponían la libertad británica a la censura católica, y no hay teoría de la libertad de expresión que sea siempre inmune a las referencias a la superioridad moral o política. La libertad de expresión deja de ser mero observador o árbitro para convertirse en un jugador en el campo de la geopolítica. La conflagración mundial desatada en torno a las caricaturas de Mahoma muestra que una simple apelación a la libertad de expresión puede servir como una forma de proclamación de superioridad de la propia civilización. 
La controversia sobre las viñetas de Mahoma puso de manifiesto la imposibilidad de un dominio cultural en un sistema de circulación global. Hace mucho tiempo las elites musulmanas quizá pudieran controlar el modo de representar el Islam, pero en la época de Google, no hay corcho para la botella. De hecho, para los editores de muchos periódicos nacionales importantes en Europa y en Norteamérica constituyó una carga tanto ética como profesional la cuestión de si publicar o no las viñetas, y muchos perdieron su trabajo debido a esa decisión. Pero en tanto que para los periódicos supuso una presión importante, nadie persiguió a Google ni pidió la dimisión de sus jefes por dejar circular las viñetas, aunque probablemente más gente las vio por este buscador que en los periódicos. De algún modo, los medios tradicionales recibieron el impacto de los ataques, quedando los medios más modernos con una relativamente libre licencia ética. Un editor es responsable de la decisión de publicar de un modo en que un motor de búsqueda no puede serlo ${ }^{10}$.

Esto conduce al cuarto reto: la transformación de la infraestructura de los medios y de la comunicación. La historia clásica de la libertad de expresión se refería a los medios impresos. La teoría de la libertad de expresión nació al mismo tiempo que la prensa escrita. Los adultos que sabían leer constituían la audiencia de la esfera púbica (Mill en On liberty excluía sin pestañear a los niños y a los bárbaros del debate público). La filosofía liberal de la libertad de expresión tenía como presupuesto gente educada y racional que entraba en contacto con materiales cultos contenidos en páginas: ¿puede mantenerse en el caso de imágenes cambiantes y sonidos? ¿Cómo va a responder la filosofía de la libertad de expresión a la decadencia de la literatura crítica como el modo normativo cognitivo propio de los ciudadanos? La cuestión, en realidad, no radica en la forma que adoptan los medios. El mundo de las fotografías digitales y de los sonidos no es necesariamente más escandaloso que el de los cotilleos y la imprenta. El París del siglo dieciocho, como sabemos por el fascinante libro de Robert Darnton, tenía un sistema multimedia de comunicación, vibrante y a menudo vulgar, en el que los rumores y cotilleos circulaban boca a boca, en canciones y manuscritos, panfletos y libros ${ }^{11}$. El siglo veintiuno ciertamente no tiene el monopolio de la información descontrolada. Pero la avalancha

10 Peters, B., «The Search Engine Democracy: Metaphors and Muhammad», en M. MAchill y M. BeILER (eds.), Die Macht der Suchmaschinen. The Power of Search Engines, Herbert von Halem Verlag, Köln, 2007, pp. 228-241.

11 Darnton, R., «An Early Information Society: New and the Media in Eighteenth Century Paris», American Historical Review, 105 (2000), pp. 1-35. 
mbre (J.)

urable"

ger" con

be tradu-

"debiera"

jero" con

e "expre- de fotografías y sonidos ha cambiado el debate público de un modo que los investigadores llevan estudiando desde mediados del siglo veinte. Los candidatos políticos se venden en el mercado como los cereales del desayuno, según un lamento de los años cincuenta. Gracias a la televisión, el correo basura y YouTube, las campañas políticas son hoy tan coloristas y caras como siempre. El espectáculo siempre ha sido un arma de poder político, pero la fotografía instantánea lo ha llevado del terreno de las grandes plazas al de la intimidad: hoy el debate político se ve afectado por suspiros, estornudos, gestos, estilos de peinado y comentarios extemporáneos que, una vez captados por la cámara, pueden hundir a las personas. El punto final de la carrera hacia el Senado de Virginia en 2006 parece que fue un videoclip del candidato perdedor colgado en YouTube en el que utilizaba el oscuro insulto étnico «macaca». Sócrates se lamentaba de que la escritura -al detener las alas de la palabra- estaba cambiando la vida filosófica en la antigua Atenas. Nosotros sabemos hoy cómo la imagen y los sonidos -al capturar los actos de los líderes- han cambiado la vida pública.

La cuestión aquí es tanto la organización social de la comunicación cuanto las propiedades sensoriales de los medios mismos. En el momento de máxima popularidad del broadcasting ${ }^{12}$ entre 1930 y 1980, la radio y la televisión en los países industriales se dirigían a audiencias nacionales en forma de servicio público. Había una clara economía moral en la programación: el contenido de los medios electrónicos era siempre «decente» (por ejemplo, estaba diseñado con gustos y valores comunes), en tanto que la cultura impresa era el vehículo para los gustos y los valores minoritarios. La «decencia» era una espada de dos filos: al tiempo que mantenía a la programación alejada de extremos «inapropiados», también lo hacía respecto a innovaciones artísticas o avances éticos. De nuevo había vías más o menos claramente diferenciadas para los gustos de la masa y para los contenidos especiales. Si alguien quería filosofía existencialista, física cuántica o pornografía, debía dirigirse a medios de circulación baja pero altamente diferenciadores como los libros. Porque la radio, la televisión y los periódicos eran medios de circulación masiva, y eran seguidos sabiendo que otros los estaban siguiendo al mismo tiempo. La consumición colectiva producía una comunidad imaginada de otros con los que uno podría entrar en conversación. Que el broadcasting se dirigiera a la masa creaba un conjunto de

12 NE. Mantenemos ese término por economía de lenguaje, puesto que su traducción en castellano sería «producción masiva y popular de radio y televisión». 
inhibiciones morales en la interpretación, para bien y para mal. La regulación moral colectiva del consumo de los medios ha ido progresivamente decayendo a lo largo de los últimos años. La influencia de los horarios de programación y la multiplicación de canales han hecho que la elección de los medios sea cada vez más cuestión de discreción e inclinación privada. Los medios de masas heredan así la antigua desinhibición que una vez prevaleció para los materiales privados impresos. Algunos predicen que el futuro de la TV descansa en miniprogramas diseñados para ser vistos por individuos a través de sus móviles y a su conveniencia. YouTube invita a sus usuarios a «broadcast yourself». Este eslogan fija con concisión la reorganización de los contenidos desarrollada en las pasadas décadas. Si broadcasting fue una vez una tarea colectiva e impersonal, hoy es un medio de autoexpresión individual ${ }^{13}$.

Clave en la transformación de los medios de comunicación en relación con la filosofía de la libertad de expresión es la generalización de la pornografía. Es una de las grandes historias de nuestro tiempo. Aquí, de nuevo, su llegada al centro de la cultura popular es tanto el resultado de transformaciones éticas como de decisiones sociales (o quizá de la falta de tales decisiones). Desde su invención como una categoría política en el siglo dieciocho hasta mediados y finales del siglo veinte, la pornografía moderna fue sobre todo una cuestión literaria. Hoy, la pornografía es casi exclusivamente una cuestión de fotografías. La pornografía histórica ha sido siempre un terreno de prueba experimental para los nuevos medios, y toda nueva tecnología visual en las últimas dos centurias, desde el daguerrotipo, a la postal, y el estereoscopio a través del kinetoscopio y el cine, han tenido usos pornográficos. Pero en cada uno de estos casos, el acceso y la circulación fueron limitados. Hoy un par de tecleos en Google pueden conjurar contenidos con una velocidad e indiscriminación sin precedentes. La pornografía se ha mudado de tiendas especializadas, de correos y de publicaciones de circulación clandestina a la casa y la oficina. Ha saltado de la imprenta a pixels. Adopta la forma de las modas que la gente usa, los gestos de la gente y quizá su efecto más importante se produzca en el campo vital, aunque inmensurable, de la imaginación colectiva. Convertir algo tan esencial y misterioso para nuestra humanidad como la sexualidad en algo expuesto ad nauseam sin atender al contexto o a la conveniencia de su expresión

13 Ver Katz, E., «And Deliver us from Segmentation», Annals of the American Academy of Political and Social Science, 546 (jul 1996), pp. 22-33; y PeTERS, J. D., «Media and Communications», en J. BlaU (ed.), Blackwell Companion to Sociology, Oxford 2001, pp. 16-29. 
me parece una forma potencial de suicidio de la civilización. En este punto el veneno podría ser excesivamente letal para practicar la medicina homeopática. La aparición de la pornografía como una industria multibillionaria es, o debería ser, un reto enorme para la confianza clásica liberal de que todo vale. En condiciones radicalmente diferentes de comunicación, no deberíamos seguir utilizando los tópicos de la Ilustración. Uno de los problemas más recurrentes de la historia y la filosofía de la libertad de expresión es precisamente cómo puede coexistir la tolerancia liberal con un sentido de lo sagrado ${ }^{14}$.

El reto final es el resurgir de la religión. Una de las narraciones del pensamiento moderno es la secularización, el supuesto fin de la religión. Los historiadores han mostrado lo erróneo de esta narración desde diversas perspectivas, pero particularmente lo ha hecho el enorme papel político jugado por los llamados «fundamentalistas»-cristianos en los Estados Unidos, judíos en Israel, hindús en la India y musulmanes en muchas naciones-. La aparición de la religión en el escenario mundial hoy no es una simple regresión a una situación histórica anterior. La religión es en muchos casos una crítica radical de y una alternativa a la modernidad capitalista. Ofrece formas de solidaridad que se oponen a la semilla neoliberal; ofrece vivencias y una noción de las virtudes que trasciende el consumismo moderno y su cultura de autorrealización a través del placer. Servicio, perdón, castidad, obediencia, sacrificio (ciertamente la vida moderna nunca apostó por esas virtudes). La esfera pública liberal se apoya sobre una visión moderna del alma y una definición secular de la razón. Al mismo tiempo, uno de los logros permanentes del pensamiento liberal de los inicios de la Europa moderna es la separación entre el Estado y la Iglesia, ya que hizo espacio para la conciencia privada, para la tolerancia, el disenso religioso y la innovación.

Pero la tolerancia de lo distinto descansaba sobre un compromiso: todos tenían que obedecer a la razón secular en la vida pública. El filósofo alemán Jürgen Habermas exploró hace algunos años el precio que la esfera pública liberal exige a los creyentes. Esto constituye un giro interesante en un orgulloso defensor marxista de la Ilustración, y quizá deba algo a su amistad con el antiguo profesor alemán que después fue conocido como Papa Benedicto XVI ${ }^{15}$.

14 Ver Steiner, G., On Difficulty and Other Essays, Oxford University Press, Oxford, 1978, pp. 61136. También Nubiola, J., «Torturas y pornografía: la degradación de la humanidad», Pensar en libertad, Eunsa, Pamplona, 2007, pp. 119-122.

15 Ver Habermas, J. y RatZinger, J., Dialektik der Säkularisierung, Herder, Freiburg 2005; y HABERMAS, J., «Religion in the Public Sphere», Holberg Prize adress, Bergen, 2005. 
En la esfera pública liberal, los creyentes tienen un hándicap cognitivo. Han de utilizar un segundo idioma puesto que su lengua materna está proscrita en esa esfera. Tienen que hacer frente a una carga asimétrica en el debate, puesto que deben traducir su visión a un idioma secular. Para tomar parte, los creyentes deben dividir sus conciencias, siendo así que creer implica precisamente la referencia a una conciencia total, no dividida. Habermas, con la característica fuerza de su pensamiento, admite que determinadas formas de razón discriminan a determinadas clases de personas. La creación de un campo público genuinamente pluralista exigiría visiones pluralmente flexibles del campo público mismo. El liberalismo quiere ser el mediador imparcial de la vida pública, el árbitro. Pero dice a todo el mundo que juegue con las reglas liberales. Presupone una respuesta para la cuestión central que hay que debatir: ¿cómo debe ser el debate mismo? La misma idea de un debate abierto sobre todos los tópicos resulta ofensiva para algunas personas y el liberalismo tiene el deber de defender su postura en vez de asumir un estatus, como un metalenguaje sobreentendido. Aquí también la esfera pública liberal tiene una oportunidad de auto revisión creativa. Los liberales tendrán que aprender a ser pluralistas, incluso sobre la cuestión del pluralismo. Como señala Charles Taylor, el liberalismo no es un entramado neutral en el que se desarrolla la vida pública; es un «credo de lucha» con una visión particular de lo que la vida política debería ser.

Estos retos piden una filosofía de la libertad de expresión más hospitalaria y capaz. Hay una fuente para tal filosofía que puede parecer sorprendente. San Pablo fue durante largo tiempo un héroe para la Reforma y hasta tiempos recientes no ha sido en absoluto de exclusiva propiedad de los teólogos. En la vida intelectual contemporánea muchos se vuelven a sus epístolas y las encuentran sorprendentemente relevantes para los problemas de nuestro tiempo. El mensaje espiritual de Pablo en relación con la cruz va de la mano de un mensaje social acerca de cómo compaginar diferencias reales -judío y gentil, hombre y mujer, esclavo y libre- que encontramos dentro de una misma comunidad. Fue un teórico de la sociedad multicultural mucho antes de que hubiéramos aprendido a usar esos términos. También fue un teórico de la libertad. Nada es más característico de sus escritos que el tema de la liberación y la libertad. Preparando el escenario a los modernos liberales, hizo preguntas valientes y peligrosas sin miedo: ¿Debemos pecar para atraer la gracia? ¿Es pecado la ley? ¿Está maldito Dios? En sus cartas, andaba al borde del abismo: su mente inquisitiva no eludía ningún tema, aunque siempre se retiraba al final, estremecido, con un estremecimiento «ique no sea así!’. Enseñó que todo está permitido, lo que justifica las doctrinas libertarias. Pero también enseñó que 
no todo nos conviene, lo que justifica una política de sensibilidad hacia los que piensan o sienten de modo diferente. Pablo proclamó tanto la libertad como el respeto: desde su punto de vista, la mente libre debía evitar dañar mentes más débiles. Pablo hubiera odiado la censura, pero también la arrogancia y la falta de atención a los demás. El hubiera dicho que, si el valor europeo del debate abierto es realmente mejor, debería demostrarlo, no por una audacia egoísta sino por amor al extranjero.

Quizá haya un Pablo para una época post-Protestante. Su propuesta en relación con la libertad de expresión sería la de la vieja fórmula de la libertad absoluta ligada a una absoluta responsabilidad. Aplicar (críticamente por supuesto) las ideas de Pablo a la esfera pública tendría dos efectos beneficiosos. Evitaría que el debate se polarizara entre la ilustración secular y los creyentes ignorantes. Consentir que todos hablen en público es mucho mejor que hacer que los creyentes caigan en formas no liberales de acción pública. Pablo también nos recuerda la vieja herencia liberal según la cual necesitamos la libertad de expresión, no porque sabemos mucho sino más bien porque nos equivocamos con mucha facilidad. El liberalismo debe ser un gran maestro de humildad: constantemente nos recuerda nuestra infinita capacidad de equivocarnos. El liberalismo, si quiere ser sincero consigo mismo, precisa arriesgarse a una rigurosa autocrítica de sus propios presupuestos -especialmente de su tendencia a monopolizar la vida pública y su desconfianza hacia formas de razonamiento no secularizadas-. Si no lo hace, se arriesga a ser el arma ideológica de una lucha geopolítica que sólo dividirá más aún el siglo veintiuno en facciones guerrilleras.

Los liberales de hoy deberían plantearse abandonar su pretensión de altura moral. Les acecha la tentación, dado el extremismo de algunas posturas, de quedarse en sus cuarteles. Pero en lugar de imitar un mundo en blanco y negro, los liberales pueden reconocer y anticipar la otra postura. La paleta liberal tiene una interminable serie de tonos grises. En los matices descansa su arte. Los liberales podrían considerar la posibilidad de que una cultura pudiera de forma programática elegir que algunas cosas no se representaran públicamente. En un mundo que se está ahogando en imágenes, tal vez esta afirmación fuera, después de todo, el comienzo de la sabiduría. Podríamos discutir vigorosamente acerca de qué cosas deberían ser las que se evitaran, pero todos, incluso los más recalcitrantes libertarios de la expresión, sostendrían que hay algo sagrado, sea sexo, religión, política, privacidad o el principio de libertad de expresión mismo. Sostener una virtud a expensas de otras es inmaduro. El hecho trágico, como mostró el gran liberal Isaiah Berlin, es que muchos 
bienes y valores compiten por nuestra atención y vasallaje, lo que impide una síntesis o reconciliación final. La vitalidad de la esfera pública liberal requiere escuchar también las críticas sobre su forma y no sólo sobre su contenido. Una política de debate absolutamente abierto que no tenga en cuenta las sensibilidades puede que no sea el único camino para descubrir la verdad. Si los liberales no redescubren el arte de pintar con gris estamos condenados a un futuro en el que sólo los liberales estén representados en la esfera pública en tanto que los demás tendrán que limitarse a tácticas iliberales para conseguir ser oídos. Sin duda, no hay nada peor. Pablo combinó un respeto radical por la libertad de hacer preguntas con un respeto más profundo aún por el bienestar del vecino. Lo que la filosofía de la libertad de expresión precisa hoy es precisamente esa delicada mezcla entre libertad y $\operatorname{amor}^{16}$.

16 Una versión más completa de algunos de los argumentos de este trabajo en mi libro Courting the Abyss: Free Speech and the Liberal Tradition, University of Chicago Press, Chicago, 2005. 
0000 